\section{Disc replacement surgery}

HESHAM AL-KHATEEB

Luton and Dunstable Hospital, UK

\section{CORRESPONDENCE TO}

Hesham Al-Khateeb, 7 Spruce House, Woodland Crescent, London SE16 6YG, UK

E: drheshamalkhateeb@msn.com

Traditionally, spinal fusion surgery (rather than artificial disc surgery) has been the treatment of choice for individuals who have not found pain relief for chronic back pain through conservative treatment (such as physical therapy, medication, manual manipulation, etc.), and have remained disabled from their occupation, from their activities of daily living, or simply from enjoying a relatively pain-free, day-to-day existence. An interesting alternative to spinal fusion is the procedure of artificial disc replacement. Spinal fusion alleviates pain by immobilising the painful segment, thereby eliminating discogenic pain. Disc replacement is an attractive option because it eliminates the painful disc but maintains relative motion within the spinal segment. What follows is a review of selected internet sites providing up-to-date information for both orthopaedic surgeons and their patients.

\section{www.nice.org.uk/ipcat.aspx? $0=56892$}

The National Institute for Clinical Excellence (NICE) has issued full guidance to the NHS in England, Scotland and Wales on prosthetic intervertebral disc replacement. This is an excellent site for both orthopaedic surgeons as well as patients and provides several documents in PDF describing indications, a summary of the procedure, a literature review and specialist advisors' opinions. The site also provides an excellent document for patients considering disc replacement surgery in which it discusses the possible risks associated with disc replacement surgery. ${ }^{* * *}$

\section{www.spineuniverse.com/displayarticle.php/article1682.html}

This is an excellent introductory article to disc replacement. The site provides a brief outline of the anatomy of the intervertebral disc as well as the pathophysiology of degenerate disc disease. Treatment options are discussed and examples of currently available prostheses are shown as well as some current indications for disc replacement surgery are provided. The site also mentions current clinical trials conducted and provides god references for further reading. ${ }^{* *}$

\section{http://www.spine-health.com/research/discupdate/artificial/artifi- cial01.html}

Spine-health.com was started in August 1999 and provides relevant medical information and education for adults with back and neck pain. The site is again targeted at a patient audience and provides a brief history of the evolution of spine surgery and the pathophysiology of disc-generated back pain. The site provides a review of a range of new devices related to lumbar disc replacement and chronic back pain relief, including: disc nucleus replacement, total disc replacement and facet technologies. This website is an excellent source of information and is well laid out and easy to read. ${ }^{* * *}$

\section{www.spineuniversity.com/charite_disc/charite_disc.html}

This article provides an overview of disc replacement with the CHARITÉTMTM Artificial Disc. It is an excellent source of information directed towards patients but also contains a concise and brief description of disc replacement surgery and discusses: (i) the anatomy of the lumbar spine; (ii) rationale of a replacement disc; (iii) preparations for the operation by the patient; (iv) descriptions of the disc and the surgery; (v) potential complications of disc replacement surgery; (vi) patient care after surgery; and (vii) rehabilitation.***

\section{www.Ini.wa.gov/ClaimsIns/Files/OMD/} ArtificialDiscReplacement20041101.pdf

This website is run by the Washington State Department of Labor and Industries (L\&I) and contains a section on medical treatment guidelines which are published by L\&I as an educational tool for medical providers. This site provides a document in PDF describing the indications and criteria for disc replacement surgery and evaluates the current literature on artificial disc replacement. The various prosthesis studies are described and the document provides an excellent source for references. ${ }^{* * *}$

\section{Fracture management}

\section{PRAKASH JAYAKUMAR, STEVEN LAU}

Department of Orthopaedics \& Trauma, St Bartholemew's and The Royal London Hospital, London, UK

\section{CORRESPONDENCE TO}

Dr Prakash Jayakumar, 51 Bycullah Road, Enfield, Middlesex EN2 8PH, UK. E: pjay007@doctors.org.uk

\section{www.wheelessonline.com}

This site claims to be the most comprehensive, unparalleled, dynamic online medical textbook in existence, having over 11,000 pages and more than 5000 images to support this statement. Fractures and their management are extensively covered, with easily located areas via the numerous search options. Topics are presented in a clear format covering applied anatomy, fracture classification, examination findings, associated injuries, radiography, treatment and prognosis. Highlighted keywords allow the user to jump between subjects and there are comprehensive and relatively up-to-date references for each topic. Daily updates ensure that the most recent advances in the field are covered and you can even sign up for e-mail alerts. This 
website is a vast orthopaedic resource which is well designed and certainly one of the best around. ${ }^{* * *}$

\section{www.orthogate.com}

This website was set up with the aim of providing access to orthopaedic information on the internet. It achieves this by providing over 5000 links to orthopaedic topics, 1500 of which are aimed at orthopaedic as well as other health professionals. There are over 230 links for trauma and orthopaedics, which are selected by anatomical region. Most of the links are to the major resources including <www.wheelessonline.com>, but some rarer sites are also highlighted in the comprehensive search engine. There is a member's area with a modestly used forum and the opportunity to submit news or articles. Although this site does not directly pertain to fracture management, it provides an array of links to resources in this field which are often overlooked by other search tools. **

\section{www.trauma.org}

This site is aimed at professionals in trauma and critical care. The section dedicated to orthopaedic trauma contains a useful image bank based on the AO classification of fractures, accompanied by good schematic diagrams, $\mathrm{X}$-rays and a variety of images. Essentially, there is minimal narrative content on fracture management when compared to more specialist orthopaedic websites, however, the extensive collection in the photographic library is second to none. This site may be good for reviewing fracture patterns and images, and is an obvious choice for those creating orthopaedic presentations. ${ }^{* *}$

\section{www.orthoteers.org}

This online resource was originally developed by three orthopaedic trainees studying for their final FRCS Trauma and Orthopaedics examination in 1998, and was originally a collection of their summaries and notes! The website has grown in popularity (1.3 million hits per month by 2001) and with a recent facelift, it continues, as the developers say, to be 'an educational website for orthopaedic trainees by orthopaedic trainees'. Payment of the recently instituted subscription fee allows full access to an extensive online repository of narrative, high resolution images, downloadable e-manuals and orthopaedic communications in a Windows foldertype format. Fractures and management are described according to region and there is also an additional folder on trauma care. Fracture classifications, management principles and key references are clearly and succinctly described in the same style as the rest of this portal. This is a great site for education and examination revision in a bulletpoint fashion. Well worth a place in your 'internet favourites' folder. ****

\section{www.aofoundation.org}

This dynamic portal has been developed by the renowned $A O$ foundation by $\mathrm{AO}$ groups from over 12 countries. There are three very useful features. The 'AO surgery reference' is a registrationbased service which boasts a massive online library database of surgical procedures, decision making schematics, sources of evidence, and a variety of graphics, videos and animations. Second, the 'AO academy' section provides an e-learning online training module series taking the user through the management of various fractures. There is also an online case discussion facility with a 'case of the month', allowing the user to exchange ideas online. Finally, the 'AO innovations' section contains a 'skeleton' schematic which enables the identification of a selection of implants and instruments pertaining to the skeletal body part highlighted by the cursor. This reveals high resolution photographs and brief descriptions of the product approved by the AO technical commission and an affiliated company. Naturally there is access to the variety of world-wide AO courses and the $A O$ Orthopedic Trauma Directions bimonthly publication which explores latest advances in orthopaedic traumatology. Essentially, this is well-designed, attractive website from the organisation synonymous with the standards in fracture management. It is a must for any orthopaedic trainee.****

\section{www.mullerfoundation.com}

This site is the virtual home of the Maurice E. Muller FoundationEspana. It was named after the founding Emeritus Professor of the University of Bern in Switzerland who developed the Comprehensive Classification of Fractures, accepted by the $\mathrm{AO}$ group in 1986. There is extensive coverage of the AO classification of fractures and even a training tool with over 1000 cases with which to practice your diagnostic skills. There is an impressive atlas of internal fixation used on over 54,000 fractures, with schematic drawings of each $\mathrm{AO}$ fracture class and radiographic examples of each group. There is also a section on surgical approaches under the heading 'Vias de abordage en la osteosintesis', so use you Spanish dictionary when viewing this section! Overall, this is a very useful and attractive fracture management resource with the only disadvantage being the lack of detailed English translation in some sections. ${ }^{* * *}$

\section{http://orthoinfo.aaos.org/}

This is a good patient-orientated site developed by the American Academy of Orthopedic Surgeons. The patient education library is roughly divided into search by 'category' and search by 'regional skeletal body part' sections, which direct the user to a brief guide related to the fracture topic. Basic anatomy, classifications, mechanisms of injury, principles of management, complications and prognosis are covered in simple language. Naturally, being a US-based site, average costs for procedures and Spanish versions are available! Despite this and the lack of images, it may certainly be worth directing your patients to this portal. ${ }^{* * *}$ 